\title{
Hydrometeorological Applications: Severe Weather Precipitation Detection, Estimation, and Forecast
}

\author{
Youcun Qi, ${ }^{1}$ Qing Cao, ${ }^{2}$ Bin Yong, ${ }^{3}$ Ke Zhang, ${ }^{4}$ and Zhe $\mathrm{Li}^{1}$ \\ ${ }^{1}$ Key Laboratory of Water Cycle and Related Land Surface Processes, Institute of Geographic Sciences and Natural Resources Research, \\ Chinese Academy of Sciences, Beijing, China \\ ${ }^{2}$ Enterprise Electronics Corporation, Norman, OK, USA \\ ${ }^{3}$ Earth System Science Interdisciplinary Center (ESSIC), College Park, MD, USA \\ ${ }^{4}$ State Key Laboratory of Hydrology-Water Resources and Hydraulic Engineering and College of Hydrology and Water Resources, \\ Hohai University, 1 Xikang Road, Nanjing, Jiangsu Province 210098, China
}

Correspondence should be addressed to Youcun Qi; youcun.qi@gmail.com

Received 2 April 2017; Accepted 2 April 2017; Published 15 May 2017

Copyright (C) 2017 Youcun Qi et al. This is an open access article distributed under the Creative Commons Attribution License, which permits unrestricted use, distribution, and reproduction in any medium, provided the original work is properly cited.

Severe weather with heavy precipitation could bring unexpected hydrometeorological hazards, such as flash floods and landslides, which might become disasters and cause significant injuries, deaths, infrastructure damage, transportation paralysis, and/or many other problems. These natural hazards occur all over the world, although their frequency and intensity are quite different from region to region. Therefore, it is critically important to accurately monitor and estimate the heavy precipitation so that the occurrence and intensity of associated hydrometeorological hazards can be well identified, detected, and forecasted. Currently, the most powerful technique to monitor and study the severe weather is remote sensing (e.g., radar). Associated observations on the ground are necessary for calibrating remote sensing products, providing accurate and high-resolution precipitation estimates, improving the accuracy flash flood forecasting, and enhancing the understanding of causation and geophysical processes of these natural hazards.

Many regions in the world experience severe thunderstorms and violent tornadoes every year. In the United States (US), there are 58 tornadoes that occurred in Oklahoma only on May 03, 1999, and 45 people died and more than 600 got injured [1]. Throughout the severe weather events, the US emergency managers (EMs) use a variety of information sources, particularly radar products [2, 3], and the radar algorithms, attempting to detect, classify, and track the presence of severe thunderstorm cells, mesocyclone circulations, tornadic vortex signatures, downbursts/microbursts, and hail, among others. The severe weather detection algorithms are based on radar observations and developed suites of severe weather and aviation products [3]. The severe weather detection algorithms have evolved over years, even though the designs between the algorithms and the configurations are different. Severe weather usually comes with heavy precipitation and causes flash floods or landslides. Zhang et al. (2016) [4] developed the Multiradar Multisensor (MRMS) system to generate a suite of quantitative precipitation estimation (QPE) product with very high spatial $(1 \mathrm{~km})$ and temporal $(2 \mathrm{~min})$ resolutions. The generated QPE products are used to improve the tools for flash flood monitoring and prediction across the US [5-7]. This special issue includes selected articles that report recent investigations/advances in Severe Weather Precipitation Detection, Estimation, and Forecast through observational and numerical approaches.

Tropical rainfall generally has high-efficiency precipitation and may cause heavy precipitation in a short time. However, it cannot be directly reflected in the reflectivity field because the raindrop size is relatively small. L. Yang et al. proposed one algorithm for improving the radarderived QPE based on the vertical profile of reflectivity (VPR). Upon identifying a tropical VPR, the rainfall is classified as either tropical-stratiform or tropical-convective rainfall by a fuzzy logic (FL) algorithm. The results show that the rainfall rates match closely the gauge observations. Y. Huang et al. developed one classification system and flagged the precipitation types into five categories with radar and 
satellite data, which finally improved the accuracy of radar QPE.

Satellite-based precipitation products are expected to offer an alternate to ground-based rainfall estimates in the present and the foreseeable future. Z. Zhang et al. evaluated the performance of TRMM 3B42 precipitation products in the Yangtze River basin for the period of 2003 2010 and suggested that more attention should be paid to the influence of complex climate and topography. In northeastern France on Nov 03-04 2014, a 24-hour heavy rainfall event occurred. B. Pauthier et al. evaluated the accuracy of radar QPE at both mesoscale and local scales with two sets of rain gauge observations and suggested that the merged products could be invaluable for applications at very high resolution. With the development of high-performance computer systems and data assimilation techniques, storm-scale numerical weather prediction (NWP) models are gradually used for short-term deterministic forecasts. G. Wang et al. evaluated and corrected the precipitation forecasts of a storm-scale NWP model called the advanced regional prediction system (ARPS).

In July 2008, five people were killed by a tragic flash flood caused by a local torrential heavy rainfall in a short time in Toga River. E. Nakakita et al. analyzed this event and verified that the first radar echo aloft could be a practical and important sign for early warning of flash flood. Development of meteorological-hydrologic coupled flood forecasting model and early warning model based on the TIGGE precipitation ensemble forecast can provide the flood probability forecast, extend the lead time of flood forecast, and gain more time for decision-makers to make the right decision. In this study, precipitation ensemble forecast products from ECMWF, NCEP, and CMA were used to derive distributed hydrologic model TOPX. J. Ye et al. developed one flood forecast and early warning system for Yi River catchment.

Aerosol properties are closely related to cloud generation and severe weather precipitation. Y. Qiu et al. extracted the cloud and aerosol profiles properties with The CloudSat/CALIPSO data. They found that the mean value of cloud occurrence probability (COP) was the highest in the mixed cloud layer $\left(-40^{\circ} \mathrm{C} \sim 0^{\circ} \mathrm{C}\right)$ and the lowest in the warm cloud layer $\left(>0^{\circ} \mathrm{C}\right)$. The atmospheric humidity was more statistically relevant to $\mathrm{COP}$ in the warm cloud layer than aerosol condition. The differences in COP between the two regions in the mixed cloud layer and ice cloud layer $\left(<-40^{\circ} \mathrm{C}\right)$ had good correlations with those in the aerosol extinction coefficient. A radar reflectivity factor greater than $-10 \mathrm{dBZ}$ occurred mainly in warm cloud layers and mixed cloud layers.

There is no doubt that there are much more studies representing recent advances and research directions in Severe Weather Precipitation Detection, Estimation, and Forecast. However, the papers collected in this special issue cover a wide range of research topics and shed light on some of recent progress and ideas in the field. It will serve as valuable asset for the scientists and engineers in hydrometeorology and related fields.

\section{Acknowledgments}

We thank all the authors who contributed to this issue and all the reviewers who provide valuable, constructive comments to the manuscripts and help to improve the quality of these papers published in this issue.

Youcun Qi
Qing Cao
Bin Yong
Ke Zhang
Zhe Li

\section{References}

[1] S. Brown, P. Archer, E. Kruger, and S. Mallonee, "Tornadorelated deaths and injuries on Oklahoma due to the 3 May 1999 tornadoes," Weather and Forecasting, vol. 17, no. 3, pp. 343-353, 2002.

[2] P. Joe, D. Burgess, R. Potts, T. Keenan, G. Stumpf, and A. Treloar, "The S2K severe weather detection algorithms and their performance," Weather and Forecasting, vol. 19, no. 1, pp. 43-63, 2004.

[3] T. M. Smith, V. Lakshmanan, G. J. Stumpf et al., "Multi-Radar Multi-Sensor (MRMS) severe weather and aviation products: initial operating capabilities," Bulletin of the American Meteorological Society, vol. 97, no. 9, pp. 1617-1630, 2016.

[4] J. Zhang, K. Howard, C. Langston et al., "Multi-Radar MultiSensor (MRMS) quantitative precipitation estimation: initial operating capabilities," Bulletin of the American Meteorological Society, vol. 97, no. 4, pp. 621-638, 2016.

[5] J. J. Gourley, Z. L. Flamig, H. Vergara et al., “The FLASH Project: improving the tools for flash flood monitoring and prediction across the united states," Bulletin of the American Meteorological Society, vol. 98, no. 2, pp. 361-372, 2017.

[6] S. Zhang and H. Gao, "A novel algorithm for monitoring reservoirs under all-weather conditions at a high temporal resolution through passive microwave remote sensing," Geophysical Research Letters, vol. 43, no. 15, pp. 8052-8059, 2016.

[7] S. Zhang, H. Gao, and B. S. Naz, "Monitoring reservoir storage in South Asia from multisatellite remote sensing," Water Resources Research, vol. 50, no. 11, pp. 8927-8943, 2014. 

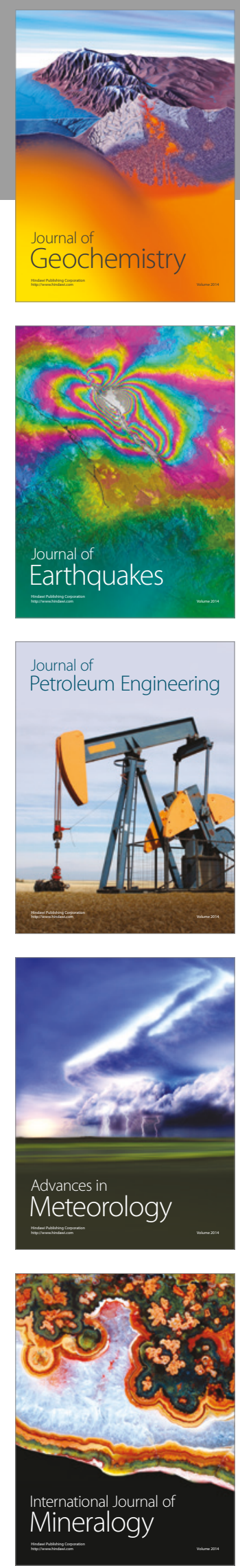
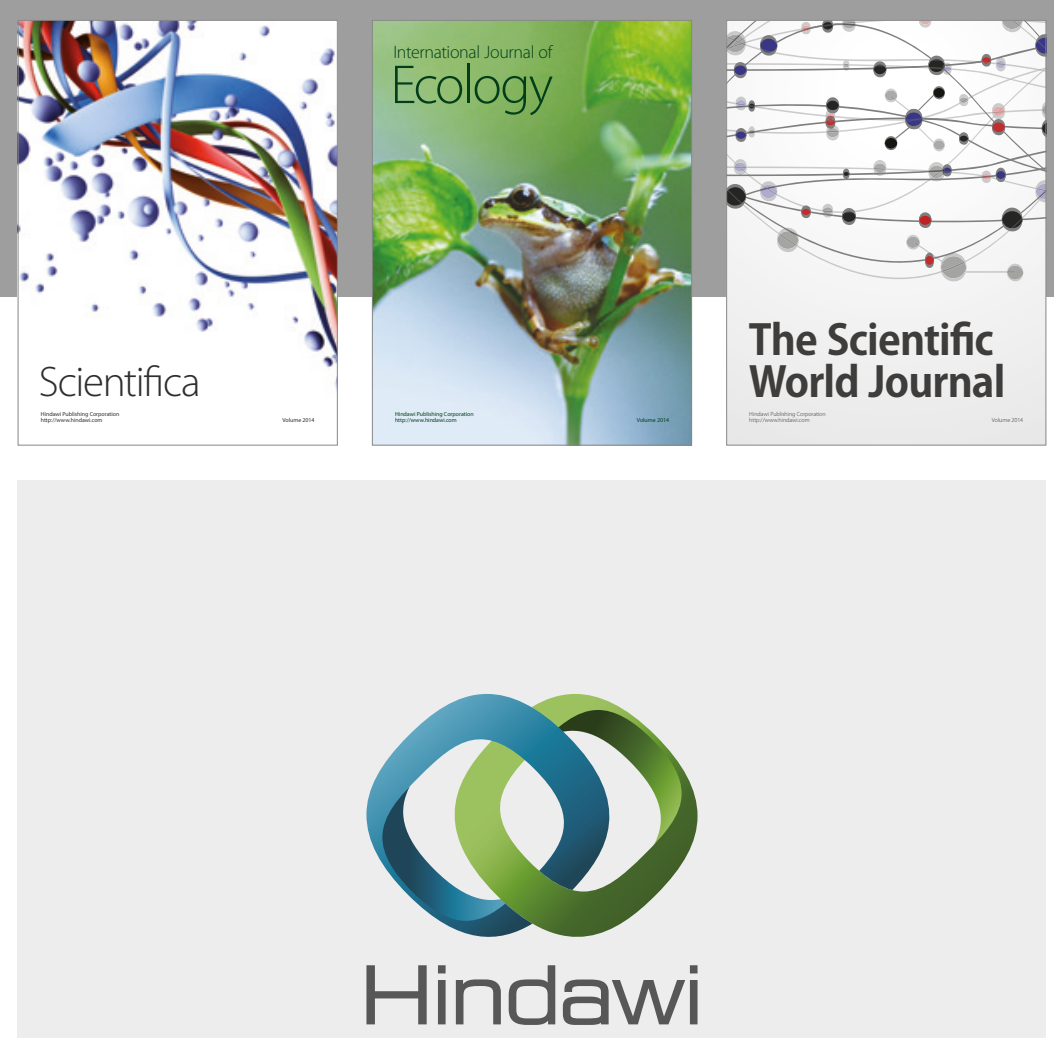

Submit your manuscripts at

https://www.hindawi.com
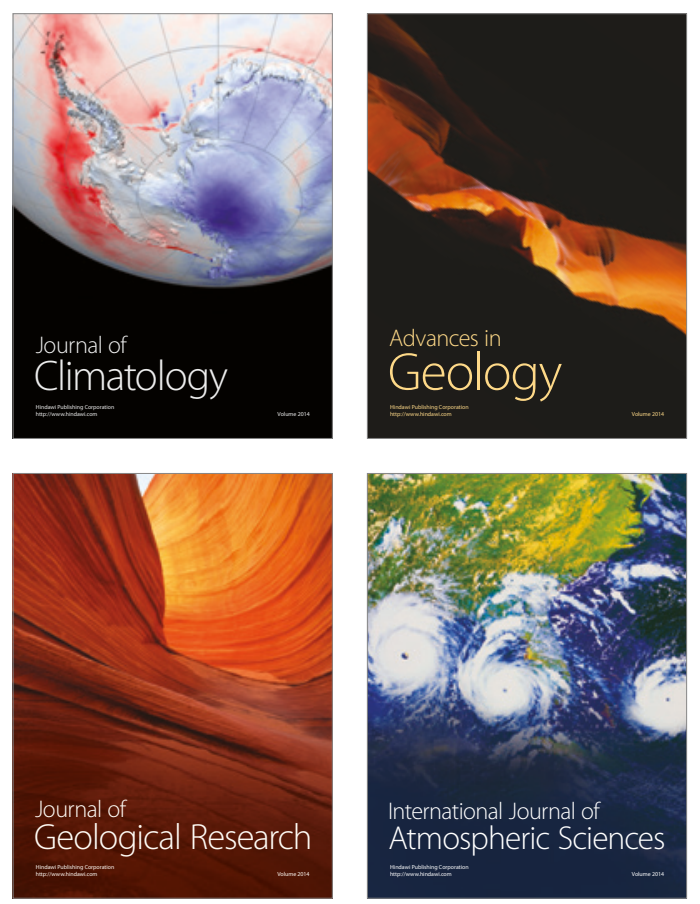

The Scientific

World Journal
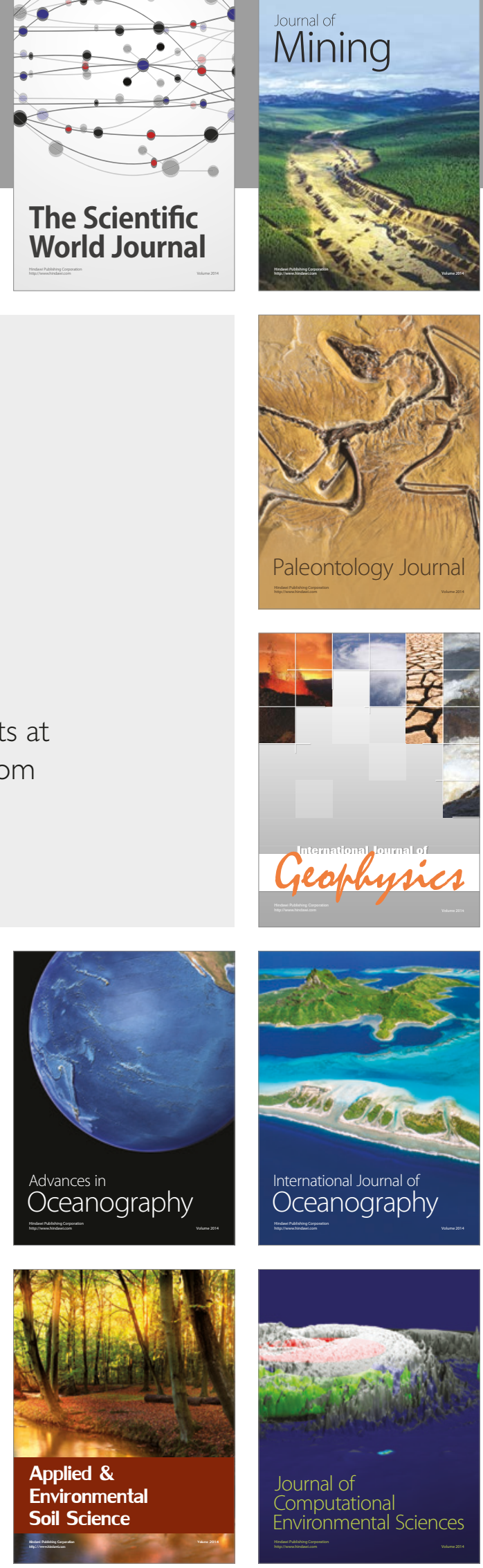